\title{
Role of Acid and Weakly Acidic Reflux in Gastroesophageal Reflux Disease Off Proton Pump Inhibitor Therapy
}

\author{
Hea Jung Sung, Yu Kyung Cho, ${ }^{*}$ Sung Jin Moon, Jin Su Kim, Chul Hyun Lim, Jae Myung Park, In Seok Lee, Sang Woo \\ Kim and Myung-Gye Choi
}

Division of Gastroenterology, Department of Internal Medicine, The Catholic University of Korea, College of Medicine, Seoul, Korea

\section{Background/Aims}

Available data about reflux patterns and symptom determinants in the gastroesophageal reflux disease (GERD) subtypes off proton pump inhibitor (PPI) therapy are lacking. We aimed to evaluate reflux patterns and determinants of symptom perception in patients with GERD off PPI therapy by impedance-pH monitoring.

\section{Methods}

We retrospectively reviewed the impedance-pH data in patients diagnosed as GERD based on results of impedance-pH monitoring, endoscopy and/or typical symptoms. The characteristics of acid and weakly acidic reflux were evaluated. Symptomatic and asymptomatic reflux were compared according to GERD subtypes and individual symptoms.

\section{Results}

Forty-two patients (22 males, mean age 46 years) were diagnosed as GERD (17 erosive reflux disease, 9 pH $(+)$ non-erosive reflux disease [NERD], 9 hypersensitive esophagus and 7 symptomatic NERD). A total of 1,725 reflux episodes were detected (855 acid [50\%], 857 weakly acidic [50\%] and 13 weakly alkaline reflux $[<1 \%]$ ). Acid reflux was more frequently symptomatic and bolus clearance was longer compared with weakly acidic reflux. In terms of globus, weakly acidic reflux was more symptomatic. Symptomatic reflux was more frequently acid and mixed reflux; these associations were more pronounced in erosive reflux disease and symptomatic NERD. The perception of regurgitation was related to acid reflux, while that of globus was more related to weakly acidic reflux.

\section{Conclusions}

In patients not taking PPI, acid reflux was more frequently symptomatic and had longer bolus clearance. Symptomatic reflux was more frequently acid and mixed type; however, weakly acidic reflux was associated more with globus. These data suggest a role for impedance-pH data in the evaluation of globus.

(J Neurogastroenterol Motil 2012;18:291-297)

Key Words

Electric impedance; Esophageal pH Monitoring; Gastroesophageal reflux

Received: February 23, 2012 Revised: April 28, 2012 Accepted: April 30, 2012

(c) This is an Open Access article distributed under the terms of the Creative Commons Attribution Non-Commercial License (http://creativecommons. org/licenses/by-nc/3.0) which permits unrestricted non-commercial use, distribution, and reproduction in any medium, provided the original work is properly cited.

*Correspondence: Yu Kyung Cho, MD

Division of Gastroenterology, Department of Internal Medicine, Seoul St. Mary’s Hospital, Banpo-daero 222, Seocho-gu, Seoul 137-701, Korea

Tel: +82-2-2258-2044, Fax: +82-2-2258-2055, E-mail: ykcho@catholic.ac.kr

Financial support: None.

Conflicts of interest: None. 


\section{Introduction}

Not all reflux episodes occurring in patients with gastroesophageal reflux disease (GERD) are accompanied by reflux symptoms. The reason that some reflux episodes evoke symptoms and the nature of the determinants of gastroesophageal reflux (GER) perception remain unclear. In patients on acid suppression therapy, the high proximal extent of refluxate and gas were important factors associated with reflux perception. ${ }^{1,2}$ Weakly acidic reflux underlies the majority of reflux episodes in patients with GERD on proton pump inhibitor (PPI) therapy and is considered the main cause of reflux symptoms occurring despite PPI therapy. ${ }^{3,4}$

Studies demonstrate that in patients with GERD not taking a PPI, the majority of symptomatic reflux episodes are acidic, and approximately one third of symptomatic reflux episodes are weakly acidic. ${ }^{5}$ Weakly acidic reflux is responsible for only a minor portion of symptomatic reflux episodes in patients off medication, highlighting their relatively minor role in symptom causation. However, acid reflux alone does not account for all of the symptoms reported by GERD patients. ${ }^{6}$ The diagnostic gain resulting from impedance testing for detecting weakly acidic reflux in patients off PPI therapy may be higher with atypical GERD symptoms ${ }^{7-10}$ Furthermore, existing data on the pathophysiology of NERD suggest that abnormal esophageal acid exposure cannot be the sole cause of these symptoms. Combined $\mathrm{pH}$ and multichannel intraluminal impedance (MII) monitoring allows characterization of reflux episodes as acid, weakly acidic, or weakly alkaline as well as assessment of their proximal extent within the esophagus and composition. Use of combined $\mathrm{pH}-\mathrm{MII}$ monitoring is bringing into focus the potential role of weakly acidic and weakly alkaline reflux in GERD and in production of symptoms associated with reflux episodes. The aim of this study was to characterize reflux episodes and determinants of symptom perception in patients not taking PPI according to GERD subtypes and individual symptoms using impedance-pH monitoring.

\section{Materials and Methods}

\section{Patients}

Approval for this retrospective study was obtained from the Catholic University of Korea Institutional Review Boards. Between January 2009 and March 2011, 24-hour ambulatory com- bined MII-pH monitoring was carried out in consecutive patients for evaluation of GERD at Seoul St. Mary's hospital, a tertiary university hospital. All patients had at least one typical reflux symptom (heartburn and acid regurgitation) or atypical symptoms (globus or chronic cough) that occurred more than twice per week. All patients underwent endoscopy within 2 months before MII-pH monitoring. Of these, 42 (22 males, mean age 46 \pm 12 years) who were diagnosed with GERD by endoscopy and combined MII-pH were enrolled in this study. They were classified as (1) erosive reflux disease (ERD); (2) $\mathrm{pH}(+)$ non-erosive reflux disease (NERD) with normal endoscopy and abnormal distal esophageal acid exposure; (3) hypersensitive esophagus with normal endoscopy, normal distal esophageal acid exposure, and positive symptom association for either acid or nonacid reflux; and (4) symptomatic NERD with normal endoscopy, normal distal esophageal acid exposure, negative symptom association, typical GERD symptoms and positive PPI test. Exclusion criteria were prior fundoplication, history of thoracic, esophageal, gastric surgery, and primary or secondary severe esophageal motility disorders.

Before $\mathrm{pH}$ monitoring, symptom assessment was performed using a reflux-symptoms questionnaire. This questionnaire included typical symptoms (heartburn and acid regurgitation), epigastric pain, epigastric soreness and atypical symptoms (eg, globus, hoarseness, chronic cough and chest pain). Symptom severity was evaluated using the 5-point Likert scale consisting of 'none', 'mild' (an occasional symptom that can be ignored, does not influence daily routine or sleep), 'moderate' (symptom cannot be ignored and/or occasionally influences daily routine or sleep), 'severe' (symptom presents more frequently during the day or night and/or regularly influences daily routine or sleep) and 'very severe' (a constant symptom and/or markedly influences daily routine or sleep). Symptom frequency (2-3 times per month, 1-2 times per week, 3-4 times per week and 5-6 times per week and daily) and most bothersome symptom were also checked. Patients whose symptom severity was from moderate to severe, occuring more than 2 episodes per week were included. Globus was defined as a sense of lump, a retained food bolus, or tightness in the throat, which was non- painful, frequently improved with eating, commonly was episodic, and was unassociated with dysphagia or odynophagia. ${ }^{11,12}$ Chronic cough was defined as cough which lasted more than 3 weeks.

Only 30 (18 males, mean age $50 \pm 16$ years) patients ( $71 \%)$ who complained of any type of reflux symptom during MII were selected for further analysis of reflux characteristics (acid/weakly 
acidic/weakly alkaline), and reflux-symptom association. Twelve patients did not complain of any symptoms during the 24-hour recording.

\section{Combined Multichannel Intraluminal Imped- ance $\mathrm{pH}$ Monitoring}

The study was carried out on an outpatient basis after at least 8 hours of fasting. PPI and all other drugs potentially affecting gastrointestinal motility and secretion were discontinued at least 2 weeks prior to the study. Esophageal impedance-pH monitoring was performed using a Sleuth ${ }^{\circledR}$ Multichannel Intraluminal Impedance ambulatory system (Sandhill Scientific, Inc., Highlands Ranch, CO, USA). The 6-channel impedance catheter-pH catheter was passed transnasally under topical anesthesia and attached $5 \mathrm{~cm}$ above the manometrically localized lower esophageal sphincter (LES) to record $\mathrm{pH}$ at $5 \mathrm{~cm}$ and impedance at 3, 5, 7, 9, 15 and $17 \mathrm{~cm}$ proximal to the LES. The $\mathrm{pH}$ and impedance signals were stored in a data-collection device. Patients were encouraged to maintain normal activity, sleep schedules and usual meals at their normal times. They were asked to record symptoms during the study period. Data from the impedance channels and the $\mathrm{pH}$ electrodes were stored on a portable data recorder (Sleuth; Sandhill Scientific, Inc., Highlands Ranch, CO, USA). At the end of the 24-hour recording period, data were downloaded onto a computer and analyzed using dedicated software (BioViewanalysis ${ }^{\circledR}$; Sandhill Scientific, Inc.).

\section{Definitions of Reflux Episodes}

Recorded $\mathrm{pH}$ data were used to classify reflux episodes as acid, weakly acidic or weakly alkaline. Definitions were as follows: (1) acid reflux: refluxed gastric juice with a $\mathrm{pH}<4$, which can either reduce the $\mathrm{pH}$ of the esophagus to $<4$ or occur when the esophagus $\mathrm{pH}$ is already $<4$; (2) weakly acidic reflux: reflux events that result in an esophageal $\mathrm{pH}$ between 4 and 7; and (3) weakly alkaline reflux: reflux episodes during which nadir esophageal $\mathrm{pH}$ does not drop below 7.

Liquid reflux was defined as a retrograde $50 \%$ drop in impedance starting distally (at the level of the LES) and propagating to at least the next two proximal impedance measuring segments. Gas reflux was defined as a rapid $(3 \mathrm{k} \Omega / \mathrm{s})$ increase in impedance $>5,000 \Omega$, occurring simultaneously in at least 2 esophageal impedance measuring segments, in the absence of swallowing. Mixed liquid-gas reflux was defined as gas reflux occurring immediately before or during a liquid reflux.

Total 24-hour esophageal acid exposure (\%) was defined as the total time at $\mathrm{pH}$ below 4 divided by the time of monitoring. Total distal esophageal acid exposure less than $4.2 \%$ over 24 hours was considered normal. The symptom index (SI) and symptom-association probability (SAP) were calculated according to the formula described previously. SI was defined as the number of symptoms associated with reflux divided by the total number of symptoms. SAP was calculated as the probability that the observed distribution could have occurred by chance. SI and SAP were considered to be positive at $\geq 50 \%$ and $\geq 95 \%$, respectively.

\section{Gastroesophageal Reflux Variables}

All reflux events were analyzed in both the upright and supine positions. Each individual reflux event was analyzed separately and classified as symptomatic or not. Reflux events were considered symptomatic if their onset occurred within a 2 minute time window before the patient activated an event marker. For example, if the onset of globus or throat discomfort was within 2 minutes after onset of reflux episodes, we considered it as a symptomatic reflux which provoked throat discomfort. For each reflux event, the following variables were determined: body position, reflux composition (liquid or mixed liquid-gas), chemical composition (acid, weakly acidic or weakly alkaline) and proximal reflux (reflux reaching the $15 \mathrm{~cm}$ impedance site). Median reflux bolus clearance time (BCT) of refluxate was defined as the time, in seconds, from the $50 \%$ drop in impedance until impedance again recovered to above this point (determined $5 \mathrm{~cm}$ above the LES).

\section{Statistical Methods}

All data were collected retrospectively. Quantitative and qualitative data are given as, respectively, median (interquartile range) and number (percentage). Comparisons between symptomatic and asymptomatic reflux episodes were performed on a per-subject basis using the Wilcoxon signed-rank tests. Comparison of the characteristics of reflux episodes preceding each symptom was performed using Mann-Whitney tests and $\chi^{2}$ tests or Fisher's exact tests, when appropriate. A $P$-value $<0.05$ was considered statistically significant.

\section{Results}

Forty-two patients (22 males, mean age 46 years old) were enrolled. Patients were classified as 17 ERD (8 males, $50 \pm 17$ years old), $9 \mathrm{pH}(+) \mathrm{NERD}(6$ males, $46 \pm 14$ years old $), 9$ hypersensitive esophagus ( 4 males, $58 \pm 11$ years old) and 7 symp- 
Table 1. Characteristics of Acid Reflux and Weakly Acid Reflux in Gastroesophageal Reflux Disease Patients

\begin{tabular}{|c|c|c|c|c|}
\hline & Acidic reflux & Weakly acid reflux & Weakly alkaline reflux & $P$-value \\
\hline Total number of reflux episodes & 855 & 857 & 13 & \\
\hline Upright position (n [\%]) & $828(97)$ & $809(94)$ & $13(100)$ & 0.320 \\
\hline \multicolumn{5}{|l|}{ Contents (n [\%]) } \\
\hline Liquid & $343(40)$ & $401(47)$ & $10(77)$ & 0.051 \\
\hline Mixed & $512(60)$ & $447(52)$ & $3(23)$ & 0.052 \\
\hline Gas & $0(0)$ & $9(1)$ & $0(0)$ & 0.052 \\
\hline Proximal reflux episodes (n [\%]) & $620(73)$ & $470(55)$ & $8(62)$ & 0.050 \\
\hline $\mathrm{pH}$ drop (median delta $[25 \%-75 \%])^{\mathrm{a}}$ & $3.7(2.5-4.5)$ & $0.7(0.4-1.3)$ & $0.3(0.2-0.7)$ & 0.001 \\
\hline Bolus clearance time $(\text { median sec }[25 \%-75 \%])^{a}$ & $11.6(5.7-22.6)$ & $9.4(3.9-20.5)$ & $7.9(3.6-19.5)$ & 0.001 \\
\hline Number of symptomatic reflux ${ }^{\mathrm{a}}(\mathrm{n}[\%])$ & $130(15)$ & $69(8)$ & $2(15)$ & 0.001 \\
\hline Typical symptoms & $22(3)$ & $4(1)$ & $2(15)$ & 0.050 \\
\hline Belching & $100(12)$ & $51(6)$ & $0(0)$ & 0.766 \\
\hline Globus & $8(1)$ & $14(2)$ & $0(0)$ & 0.005 \\
\hline
\end{tabular}

${ }^{\mathrm{a}} \chi^{2}$ tests, acid reflux vs weakly acid reflux.

Table 2. Characteristics of Reflux Episodes According to Erosive Reflux Disease and Non-erosive Reflux Disease

\begin{tabular}{lccc}
\hline & ERD & NERD & $P$-value \\
\hline $\begin{array}{l}\text { Number of reflux } \\
\text { Position (n) }\end{array}$ & 623 & 1,102 & \\
$\quad$ Upright & & & \\
$\quad$ Supine & 598 & 1,024 & 0.713 \\
Contents (n [\%]) & 25 & 50 & 0.713 \\
$\quad$ Liquid & $237(38)$ & $517(47)$ & 0.002 \\
$\quad$ Mixed & $377(61)$ & $585(53)$ & 0.006 \\
$\quad$ Gas & $9(2)$ & $0(0)$ & 0.002 \\
Acidity (n [\%]) & & & \\
$\quad$ Acid & $305(49)$ & $560(51)$ & 0.727 \\
$\quad$ Weakly acid & $310(50)$ & $537(49)$ & 0.727 \\
$\quad$ Weakly alkaline & $8(1)$ & $5(0)$ & 0.069 \\
Proximal reflux episodes & $373(60)$ & $725(66)$ & 0.107 \\
$\quad$ (n [\%]) & & & \\
pH drop (median delta & $1.5(0.6-3.4)$ & $1.8(0.6-3.9)$ & 0.089 \\
$\quad$ 25\%-75\%]) & & & \\
Bolus clearance time & $10.7(5.4-21.1)$ & $12(6.2-23.2)$ & 0.087 \\
(median sec [25\%-75\%]) & & & \\
\hline
\end{tabular}

ERD, erosive reflux disease; NERD, non-erosive reflux disease.

tomatic NERD (4 males, $36 \pm 13$ years old). Fourteen patients complained predominantly of typical symptoms, and 26 of predominantly atypical symptoms. During the monitoring period, 30 patients $(71 \%)$ reported at least 1 episode of symptom such as heartburn, regurgitation, globus or belching (11 ERD, 6 $\mathrm{pH}[+]$ NERD, 9 hypersensitive esophagus and 4 symptomatic NERD) and were included for further analysis of reflux-symptom association.

\section{Characteristics of Acid and Weakly Acidic Reflux}

A total of 1,725 reflux episodes occurred during $\mathrm{pH}$ monitoring, including 855 acid (49.6\%), 857 weakly acidic (49.7\%) and 13 weakly alkaline reflux $(0.8 \%)$. The majority of reflux episodes occurred while patients were in the upright position. More reflux episodes reached the proximal esophagus ( $73 \%$ vs $55 \%$ ), and median bolus clearance time measured at $5 \mathrm{~cm}$ from LES was longer (11.6 [5.7-22.6] vs 9.4 [3.9-20.5] seconds) in acid reflux than in weakly acidic reflux. More reflux episodes were symptomatic in acid reflux $(P<0.01)$; however, in the symptomatic reflux episodes, globus associated reflux was more common in weakly acid reflux than acid reflux $(20 \%$ vs $6 \%, P<0.05)$ (Table 1).

Acidity, nadir $\mathrm{pH}$, and time of refluxate bolus clearance did not differ between ERD and NERD patients. The total number of mixed reflux was higher in ERD patients than in patients with NERD (61\% vs 53\%); however, the proportion of mixed reflux to total reflux episodes was various among patients with ERD or NERD (Table 2).

\section{Characteristics of Symptomatic Reflux Episodes}

We analyzed a total of 1,074 reflux episodes in 30 patients. Of these, 110 (10\%) reflux episodes were symptomatic, and 964 asymptomatic. Median (25-75th) number of symptomatic reflux episodes per a patient was 4 (2-9) (range 1-28). Compared with asymptomatic reflux episodes, symptomatic reflux episodes had a higher proportion of mixed reflux $(67 \%$ vs $56 \%, P<0.01)$ and acid reflux (67\% vs $46 \%, P<0.01)$, as well as a greater $\mathrm{pH}$ drop (Table 3). 
Characteristics of reflux episodes according to GERD subtype are shown in Figure. In ERD and symptomatic NERD, symptomatic reflux episodes were more frequently preceded by acid reflux episodes and a larger $\mathrm{pH}$ drop compared with asymptomatic reflux episodes. However, there were no definite symptom-related factors in $\mathrm{pH}(+) \mathrm{NERD}$ or hypersensitive esophagus.

\section{Characteristics of Symptomatic Reflux Episo- des According to Each Symptom}

The 110 symptomatic reflux episodes consisted of 19 epi-

Table 3. The Characteristics of Symptomatic Reflux Episodes Versus Asymptomatic Reflux Episodes

\begin{tabular}{lccr}
\hline & $\begin{array}{c}\text { Symptomatic } \\
\text { reflux episodes }\end{array}$ & $\begin{array}{c}\text { Asymptomatic } \\
\text { reflux episodes }\end{array}$ & $P$-value \\
\hline $\begin{array}{c}\text { Total number of reflux } \\
\text { episodes }\end{array}$ & 110 & 964 & \\
Contents (n [\%]) & & & \\
$\quad$ Liquid & $36(37)$ & $411(43)$ & \\
Mixed & $74(67)$ & $544(56)$ & 0.039 \\
Gas & $0(0)$ & $9(1)$ & \\
Acidity (n [\%]) & & & \\
Acid & $74(67)$ & $446(46)$ & $<0.001$ \\
Weakly acid & $35(32)$ & $507(53)$ & \\
$\quad$ Weakly alkaline & $1(1)$ & $11(1)$ & \\
Proximal reflux episodes & $78(71)$ & $609(63)$ & 0.171 \\
(n [\%]) & & & \\
pH drop (mean \pm SD, & $2.8 \pm 1.7$ & $2.2 \pm 1.8$ & $<0.001$ \\
$\quad$ delta) & & & \\
Bolus clearance time & $10.7(7.3-18.0)$ & $11.5(5.7-21.9)$ & 0.500 \\
(Median sec [25\%-75\%]) & & & \\
\hline
\end{tabular}

sodes of regurgitation, 12 of globus and 79 of belching (Table 4). Reflux episodes associated with regurgitation were more frequently mixed reflux (83\%) and acidic (89\%), more frequently reached the proximal esophagus $(83 \%)$, and had a greater $\mathrm{pH}$ drop $(3.4 \pm 1.4)$, whereas globus was more associated with weakly acidic reflux (58\%). The proportions of acid reflux episodes, mixed reflux episodes, and $\mathrm{pH}$ drop in reflux associated with

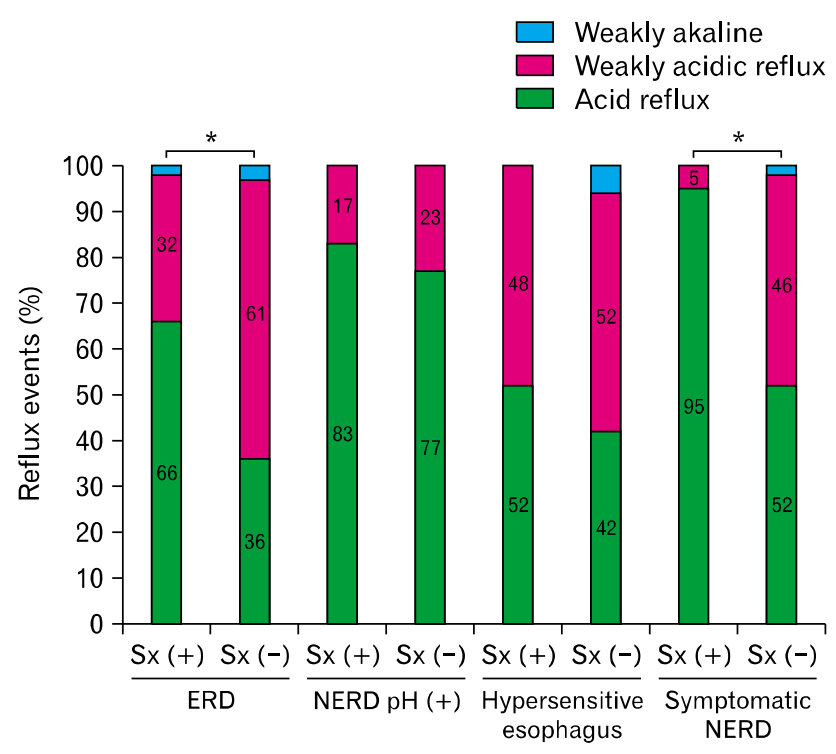

Figure. Comparison of symptomatic reflux episodes versus asymptomatic reflux episodes according to gastroesophageal reflux disease subtypes. In patients with erosive reflux disease and symptomatic non-erosive reflux disease patients, symptomatic reflux was more frequently acidic $\left({ }^{*} P<0.05\right)$. Sx, symptom; ERD, erosive reflux disease; NERD, non-erosive reflux disease.

Table 4. The Characteristics of Symptomatic Reflux Episodes According to Individual Symptom

\begin{tabular}{|c|c|c|c|c|}
\hline & Globus & Belching & Regurgitation & $\begin{array}{c}\text { Asymptomatic reflux } \\
\text { episodes }\end{array}$ \\
\hline Number of reflux & 12 & 79 & 19 & 964 \\
\hline \multicolumn{5}{|l|}{ Contents (n [\%]) } \\
\hline Liquid & $7(58)$ & $26(33)$ & $3(16)$ & $411(43)$ \\
\hline Mixed & $5(42)$ & $53(67)$ & $15(83)$ & $544(56)$ \\
\hline Gas & $0(0)$ & $0(0)$ & $0(0)$ & $9(1)$ \\
\hline \multicolumn{5}{|l|}{ Acidity (n [\%]) } \\
\hline Acid $^{\mathrm{a}}$ & $5(42)$ & $52(66)$ & $17(89)$ & $446(46)$ \\
\hline Weakly acid & $7(58)$ & $27(34)$ & $2(11)$ & $507(53)$ \\
\hline Weakly alkaline & $0(0)$ & $0(0)$ & $0(0)$ & $11(1)$ \\
\hline Proximal reflux episodes (n [\%]) & $9(75)$ & $52(66)$ & $15(83)$ & $609(63)$ \\
\hline $\mathrm{pH}$ drop (mean $\pm \mathrm{SD}$, delta) & $2.0 \pm 1.6$ & $2.9 \pm 1.7$ & $3.4 \pm 1.4$ & $2.2 \pm 1.8$ \\
\hline Bolus clearance time (median sec [25\%-75\%]) & $13.5(3.6-83.1)$ & $10.5(7-16)$ & $12.1(8.6-23.1)$ & $11.5(5.7-21.9)$ \\
\hline
\end{tabular}

${ }^{\mathrm{a}} P<0.05$, regurgitation vs other symptoms. 
belching were between regurgitation and globus.

\section{Discussion}

We investigated the characteristics of reflux episodes and reflux-symptom associations in patients with GERD not taking PPI. In this study, the proportion of acid and weakly acidic reflux in patients with GERD was almost identical (each 49.6\%). Weakly alkaline reflux accounted for $<1 \%$ of all reflux episodes. Patients whose symptoms were predominantly atypical and who were documented as ERD or $\mathrm{pH}(+)$ NERD were included, which may explain the lower proportion of acid reflux and higher proportion of weakly acidic reflux compared with a systematic review $(63 \%$ [95\% CI, 59-67] of acid reflux and 37\% [95\% CI, 33-41] weakly acidic reflux). The proportion of acid and weakly acidic reflux episodes did not differ between ERD and NERD groups, likely because all ERD patients were diagnosed with mild esophagitis (Los Angeles classification A).

The characteristics of acid reflux differed from those of weakly acidic reflux. In acid reflux, proximal reflux events were more frequent, and mixed liquid and gas reflux was more common. Additionally, bolus clearance time from the distal esophagus was longer. The esophageal mucosal injury caused by acid reflux was related to acidity and a longer bolus clearance time. These data suggest that acid reflux is more responsible for symptom generation and esophageal mucosal injury. Symptomatic reflux was more commonly related to acid reflux. Fifteen percent of acid reflux, but only $8 \%$ of weakly acidic reflux, was related to symptoms. However, globus was more commonly associated with weakly acidic reflux. Another study also suggested a relationship between atypical symptoms and weakly acidic reflux. ${ }^{13}$ This result also supports the role of impedance-pH monitoring in the evaluation of globus.

Sixty-seven percent of reflux symptom episodes were associated with acid reflux episodes; $33 \%$ of symptomatic reflux episodes were associated with weakly acidic or weakly alkaline reflux. This suggests that determinants of symptoms differ among GERD subtypes. Although the group population was too small to draw the conclusion in this study, acid reflux episodes and gas-containing mixed reflux episodes played a major role in eliciting symptoms in ERD and symptomatic NERD but were not responsible for symptom perception in $\mathrm{pH}(+) \mathrm{NERD}$ or hypersensitive esophagus. Thus, PPI responsiveness will likely be better in patients with ERD and symptomatic NERD than in those with hypersensitive esophagus. NERD patients are a heteroge- neous group. All symptomatic NERD defined in this study responded to PPI therapy and were not classified as functional heartburn according to the Rome III criteria.

Existing data on the pathophysiology of NERD suggests that abnormal esophageal acid exposure cannot be the sole cause of symptoms. These findings support the concept that reflux volume-induced distension may be responsible for these symptoms. Emerenziani et $\mathrm{al}^{14}$ reported that in NERD patients, the presence of gas in the refluxate significantly enhanced the probability of reflux perception and emphasize the role of gas as an enhancer of symptoms. One of the mechanisms by which weakly acidic or weakly alkaline reflux is believed to generate esophageal symptoms is mechanical stimulation; large volumes of refluxate can trigger heartburn irrespective of its acidity.

Typical symptoms were more related to acidic and mixed reflux, whereas globus was associated with weakly acidic and gascontaining reflux. There are few data regarding the factors involved in generation of atypical symptoms, although these have been supposed to be related to non-acid reflux. Impedance-pH studies will be valuable for assessing globus. Our findings explain the lower responsiveness of PPI to extraesophageal symptoms. Belching was a common complaint during $\mathrm{pH}$ monitoring. Belching is a physiological phenomenon and is defined as GER of gas. Belching and reflux thus occur through the same mechanism. With impedance monitoring, transport of gas and liquid in the esophagus can be monitored, and use of this technique has shown that most reflux episodes indeed consist of both a liquid and a gaseous component. As mentioned above, GER of gas distends the esophageal body, and this distention can trigger heartburn and chest pain. ${ }^{15}$ Indeed, some patients with GERD reported the sensation of heartburn during reflux episodes containing only gas. ${ }^{16}$ The impedance patterns of belching in patients in this study had different characteristics from the definition of belching. Belching was not always gas-containing reflux. Therefore, it cannot be classified as either supragastric or gastric belching. One of the explanations is that patients' expression of belching in this study may be different from criteria of other studies. The impedance characteristics of belching were between those of regurgitation and globus, suggesting that PPI may be an effective initial treatment for belching accompanied by GER symptoms.

In summary, in patients with GERD who were not taking PPI, acid reflux represented $50 \%$ of all reflux. Acid reflux was more frequently symptomatic and had a longer bolus clearance time. Symptomatic reflux was more frequently of acidic and 
mixed type, especially in patients with ERD. However, weakly acidic reflux was more related to globus. Thus, our data suggest a role for impedance-pH assessment in the evaluation of globus.

\section{References}

1. Zerbib F, Duriez A, Roman S, Capdepont M, Mion F. Determinants of gastro-oesophageal reflux perception in patients with persistent symptoms despite proton pump inhibitors. Gut 2008;57:156160.

2. Tutuian R, MF Vela, Hill EG, Mainie I, Agrawal A, Castell DO. Characteristics of symptomatic reflux episodes on acid suppressive therapy. Am J Gastroenterol 2008;103:1090-1096.

3. Mainie I, Tutuian R, Shay S, et al. Acid and non-acid reflux in patients with persistent symptoms despite acid suppressive therapy: a multicentre study. Gut 2006;55:1398-1402.

4. Zerbib F, Roman S, Ropert A, et al. Esophageal pH-impedance monitoring and symptom analysis in GERD: a study in patients off and on therapy. Am J Gastroenterol 2006;101:1956-1963.

5. Boeckxstaens GE, Smout A. Systematic review: role of acid, weakly acidic and weaklyalkaline reflux in gastro-esophageal reflux disease. Aliment Pharmacol Ther 2010;32:334-343.

6. Koek GH, Tack J, Sifrim D, Lerut T, Janssens J. The role of acid and duodenal gastroesophageal reflux in symptomatic GERD. Am J Gastroenterol 2001;96:2033-2040.

7. Sifrim D, Dupont L, Blondeau K, Zhang X, Tack J, Janssens J. Weakly acidic reflux in patients with chronic unexplained cough dur- ing 24 hour pressure, $\mathrm{pH}$, and impedance monitoring. Gut 2005;54: 449-454.

8. Bajbouj M, Becker V, Neuber M, Schmid RM, Meining A. Combined $\mathrm{pH}$-metry/impedance monitoring increases the diagnostic yield in patients with atypical gastroesophageal reflux symptoms. Digestion 2007;76:223-228.

9. Anandasabathy S, Jaffin BW. Multichannel intraluminal impedance in the evaluation of patients with persistent globus on proton pump inhibitor therapy. Ann Otol Thinol Laryngol 2006;115:563-570.

10. Blondeau K, Dupont LJ, Mertens V, Tack J, Sifrim D. Improved diagnosis of gastro-oesophageal reflux in patients with unexplained chronic cough. Aliment Pharmacol Ther 2007;25:723-732.

11. Galmiche JP, Clouse RE, Bálint A, et al. Functional esophageal disorders. Gastroenterology 2006;130:1459-1465.

12. Rakshit R, de Caestecker J. Globus: are we any nearer to understanding it? Am J Gastroenterol 2009;104:299-301.

13. Savarino E, Marabotto E, Zentilin $\mathrm{P}$, et al. The added value of impedance-pH monitoring to Rome III criteria in distinguishing functional heartburn from non-erosive reflux disease. Dig Liver Dis 2011; 43:542-547.

14. Emerenziani S, Sifrim D, Habib FI, et al. Presence of gas in the refluxate enhances reflux perception in non-erosive patients with physiological acid exposure of the oesophagus. Gut 2008;57:443-447.

15. Kahrilas P J, DoddsWJ, HoganWJ. Dysfunction of the belch reflex. A cause of incapacitating chest pain. Gastroenterology 1987;93:818822 .

16. Bredenoord AJ,Weusten BL, Curvers WL, Timmer R, Smout AJ. Determinants of perception of heartburn and regurgitation. Gut 2006;55:313-318. 